\title{
The success factors and barriers of information technology implementation in small and medium enterprises: an empirical study in Malaysia
}

\begin{abstract}
The use of information technology (IT) among entrepreneurs is one of the critical aspects as the usage of IT effectively and efficiently will enable to increase productivity and performance in small and medium enterprises (SMEs). Previous reports revealed that SMEs in Malaysia have many concerns about the durability, competitiveness and efficiency due to problems associated such as financial, lack of information and knowledge, capability and capacity. This research is derived based on the issues related to IT implementation in SMEs in Malaysia. It determines the problems and issues related to the implementation, and identify factors for the successful implementation of IT in SMEs. The research approach includes the usage of questionnaires, interviews and case studies. Literature study identified ten critical success factors that include the management, staff, IT planning, financial, consultants, vendors, organisational culture, relationship management and change, and perception. This paper presents the success factors and the barrier of IT implementation based on the empirical study.
\end{abstract}

Keyword: Small and medium enterprise; SME; Success factors; Information technology implementation; Information technology barriers; Empirical study; Survey; Malaysia 